\title{
Classification of vocalizations by recordings from the auditory midbrain
}

\author{
Dominika Lyzwa ${ }^{1 *}$, Michael Herrmann ${ }^{2}$ \\ From Twenty First Annual Computational Neuroscience Meeting: CNS*2012 \\ Decatur, GA, USA. 21-26 July 2012
}

The temporal and spatial properties of responses to complex stimuli in the central nucleus of the inferior colliculus (ICC), the main converging station in the auditory midbrain, can provide evidence for coding principles in the auditory system and are relevant for the design of neuroprosthesis.

We study responses from guinea pigs to a set of eleven species-specific vocalizations which show a wide range of spectral contents, envelope types, frequency and amplitude modulations. The envelopes of the acoustically presented stimuli are characterized as complex or periodic impulses and have various degrees of periodicity. The frequency content ranges from harmonic strucutres to broad spectral distributions. The data analyzed were multi-unit recordings taken simultaneously from 32 positions in the ICC of guinea pigs using a double shank electrode. Peristimulus time histograms (PSTHs) of the high dimensional recordings were classified by linear discriminant analysis in order to evaluate the spatial and temporal distribution of stimulus-related information without the assumption of a specific coding scheme. Neighboring neural populations respond in a similar manner and have highly correlated PSTHs. Combining responses from different positions improves the classification performance for distant postions which do not show correlation, but not for adjacent positions.

Separability of responses along the tonotopic gradient of the ICC to vocalizations shows great variation according to their spectral properties. Low-frequency stimuli are found to be better separable in low characteristic frequency (CF) lamina than complex envelope or broad spectral stimuli. Some stimuli of the latter type (squeal, whistle) are nearly perfectly discriminated in multi-units

\footnotetext{
* Correspondence: dominika@nld.ds.mpg.de

${ }^{1}$ Dept. of Nonlinear Dynamics, Max Planck Inst. for Dynamics and Self-

Organization, Göttingen, 37077, Germany

Full list of author information is available at the end of the article
}

with high CF whereas discrimination for low-frequency stimuli is less good $(60-70 \%)$ in this region, see Figure 1. For multi-units positioned in the mid-frequency range along the tonotopic axis all stimuli can be separated at a level similar to the result obtained in the low/high CF regions for the respective preferred stimuli.

We interpret the results as a consequence of the combination of several frequencies in the vocalizations that are better covered by the widely tuned receptive fields of the neurons in the mid-frequency range than by the receptive fields of the units with $\mathrm{CFs}$ in the extreme frequency ranges.

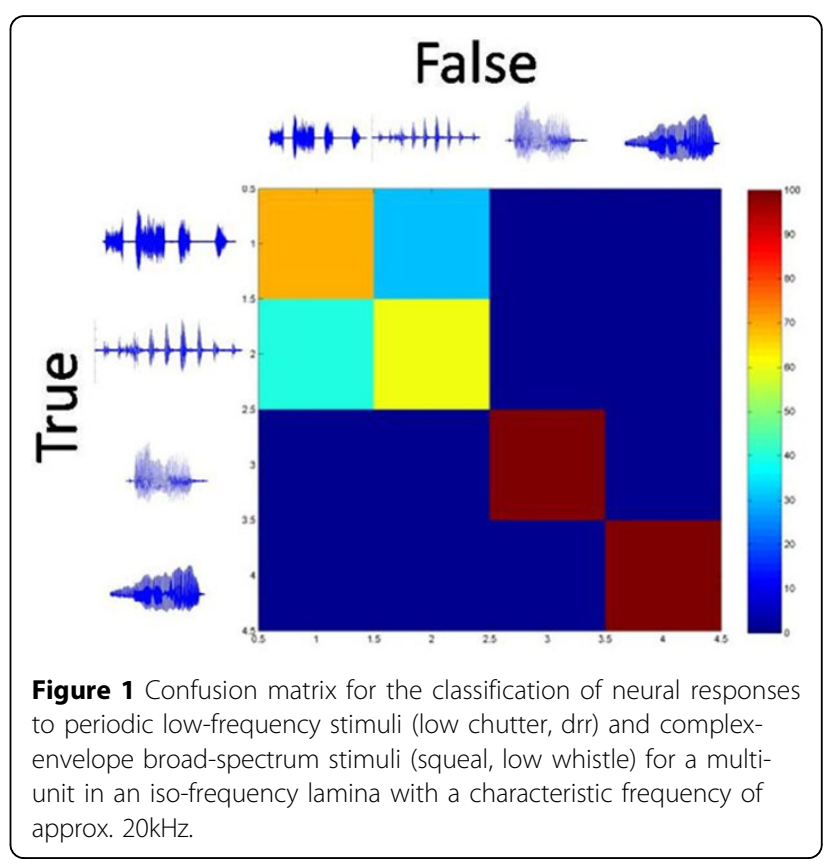




\section{Acknowledgement}

This work was supported by the BMBF in the National Network for Computational Neuro-science, grant number \#01GQ0811 to BFNT Göttingen. We would like to thank Thilo Rode, Tanja Hartmann, and Hugh H. Lim for the guinea pig recordings and vocalizations.

\section{Author details}

'Dept. of Nonlinear Dynamics, Max Planck Inst. for Dynamics and SelfOrganization, Göttingen, 37077, Germany. ${ }^{2}$ Institute of Perception, Action and Behavior, University of Edinburgh, Edinburgh, EH8 9AB, UK.

Published: 16 July 2012

doi:10.1186/1471-2202-13-S1-P89

Cite this article as: Lyzwa and Herrmann: Classification of vocalizations

by recordings from the auditory midbrain. BMC Neuroscience 201213

(Suppl 1):P89.

\section{Submit your next manuscript to BioMed Central} and take full advantage of:

- Convenient online submission

- Thorough peer review

- No space constraints or color figure charges

- Immediate publication on acceptance

- Inclusion in PubMed, CAS, Scopus and Google Scholar

- Research which is freely available for redistribution

Submit your manuscript at www.biomedcentral.com/submit 